\title{
Ku Band Hemispherical Fully Electronic Antenna for Aircraft in Flight Entertainment
}

\author{
Alfredo Catalani, ${ }^{1}$ Franco Di Paolo, ${ }^{1}$ Marzia Migliorelli, ${ }^{1}$ Lino Russo, ${ }^{1}$ \\ Giovanni Toso, ${ }^{2}$ and Piero Angeletti ${ }^{2}$ \\ ${ }^{1}$ Antenna and Sub-Millimeter Wave Section, Space Engineering S.p.A., Via dei Berio 91, 00155 Roma, Italy \\ ${ }^{2}$ Electromagnetics Division, TEC-EEA, European Space Agency, ESA ESTEC, Keplerlaan 1, PB 299, \\ 2200 AG Noordwijk, The Netherlands
}

Correspondence should be addressed to Alfredo Catalani, alfredo.catalani@space.it

Received 30 September 2008; Revised 8 January 2009; Accepted 23 March 2009

Recommended by Stefano Selleri

\begin{abstract}
The results obtained in the frame of the ESA activity "Advanced Antenna Concepts For Aircraft In Flight Entertainment" are presented. The aim of the activity consists in designing an active antenna able to guarantee the Ku band link between an aircraft and a geostationary satellite in order to provide in flight entertainment services. The transmit-receive antenna generates a single narrow beam to be steered electronically in a half sphere remaining compliant with respect to stringent requirements in terms of pattern shape, polarization alignment, EIRP, G/T, and using customized electronic devices. At the same time, the proposed solution should be competitive in terms of cost and complexity.
\end{abstract}

Copyright ( 12009 Alfredo Catalani et al. This is an open access article distributed under the Creative Commons Attribution License, which permits unrestricted use, distribution, and reproduction in any medium, provided the original work is properly cited.

\section{Introduction}

Over the last few years the public's reliance on computer networks including, but not limited to, Internet has increased exponentially. Many people today use Internet for business and entertainment. Aeronautical broadband services provisioning by satellites are becoming a reality moving from an experimental base to an operational condition.

Aircrafts use antennas for transmitting and receiving communication signals. Key aspects to consider in the design of these antennas are the aerodynamic drag, the beam pointing capability, and the receive/transmit functionality.

Concerning the aerodynamic aspects, the antenna has to exhibit the minimum impact on the aircraft in order to reduce the extra fuel consumption due to the drag of the antenna installed on the fuselage. As a rule of thumb, the height of antennas on board large aircrafts and inclusive of the radome should not exceed $30 / 40 \mathrm{~cm}$.

Concerning the beam pointing characteristics, to be operative both at equatorial routes as well as at the extreme latitudes required by polar routes, the preferred antenna solution should exhibit wide-angle beam scanning capabilities.

The possible antenna architectures 0 are based on fully mechanical [1], fully electronic [2], or "hybrid" (mechanicalelectronic) solutions $[3,4]$.

Complexity and cost of the antenna are other key factors to consider together with ability to operate simultaneously in reception and in transmission.

The principal target, in terms of antenna characteristics, is the operation in the complete $\mathrm{Ku}$ Band $(10.7 / 12.75 \mathrm{GHz}$ in receive, $14.0 / 14.5 \mathrm{GHz}$ in transmit) and the realignment of the polarization with respect to the satellite for both receive and transmit signals, with the capability to operate also with the circular polarization in receive signals.

The minimum antenna requirements in terms of operative Field of View, G/T, EIRP, and cross polar discrimination are reported in Table 1.

Regulatory aspects [5] are also considered: an antenna in transmission mode has to respect the applicable regulations for the EIRP antenna patterns expressed in terms of power per bandwidth as shown in Figure 1. 
TABLE 1: Antenna performances requirements.

\begin{tabular}{lc}
\hline Requirements & Antenna \\
\hline $\begin{array}{l}\text { Radiation gain pattern over RF band } \\
\text { Operative antenna field of view }\end{array}$ & $\begin{array}{c}\text { In agreement with }\left(^{*}\right) \\
0^{\circ}<\varphi<360^{\circ} \\
0^{\circ}<\theta<90^{\circ}\end{array}$ \\
$\begin{array}{l}\text { G/T over RF band, in the entire field of } \\
\text { view and for every selectable polarization }\end{array}$ & $>8 \mathrm{dBK}{ }^{-1}$ \\
$\begin{array}{l}\text { EIRP over RF band, in the entire field of } \\
\text { view }\end{array}$ & $>43 \mathrm{dBW}$ \\
$\begin{array}{l}\text { Number of beams } \\
\text { Cross polarization discrimination } \\
\text { (including pointing error) }\end{array}$ & 1 \\
\hline
\end{tabular}

(*) Ref. [5]

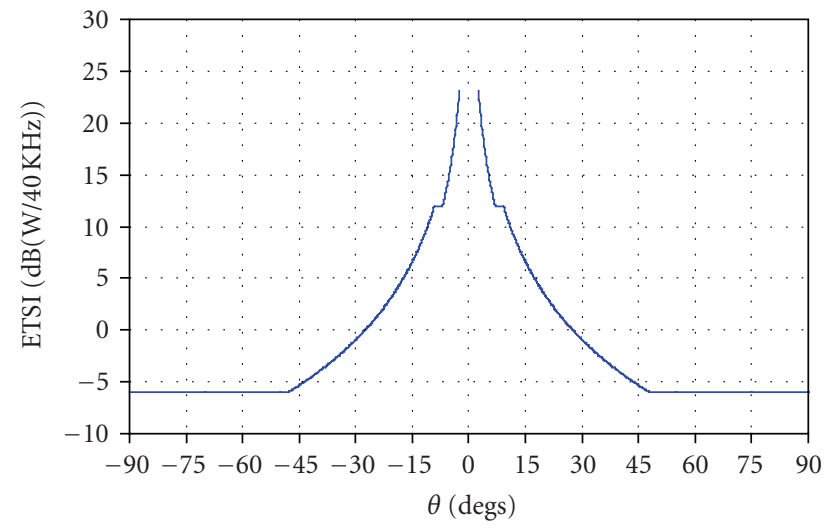

FIgURE 1: ETSI regulation mask [5].

\section{Antenna Baseline Architecture}

The proposed baseline antenna architecture is an evolution of the Hemi-Spherical Antenna Array shown in Figure 2.

This Antenna typology, due to its particular shape, once mounted on the aircraft is able to hold-on the appropriate link whatever the position of the airborne with respect to the satellite is.

In order to minimize the complexity of the antenna, the Hemi-Spherical continuous surface has been organized in flat facets. The icosahedron, a polyhedron with twenty equilateral triangles, has been selected to replace the sphere. Besides, a further division of each triangular face (obtained projecting the vertices of the triangles on the sphere) has been implemented. As a result of a dedicated optimization, the geodesic hemi-sphere with 40 facets shown in Figure 3 has been considered the geometrical candidate for the presented antenna. Each triangular face exhibits the same identical subarray; therefore the same number of radiating elements disposed on a triangular lattice.

The final optimized antenna is combining on the same aperture of the receive-transmit capabilities, exhibiting a diameter of $84 \mathrm{~cm}$, a height of $39 \mathrm{~cm}$, and a weight in the order of $90 \mathrm{Kg}$. The number of radiating elements is 1440 with an interspacing comparable to the wavelength at the Tx higher frequency.

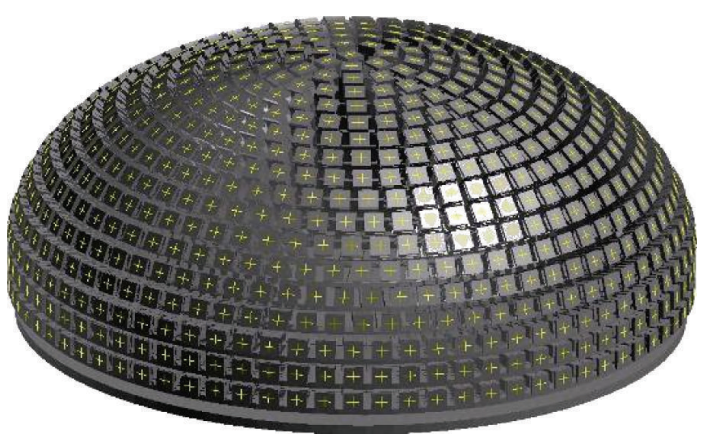

FIgURE 2: Hemi-spherical array.

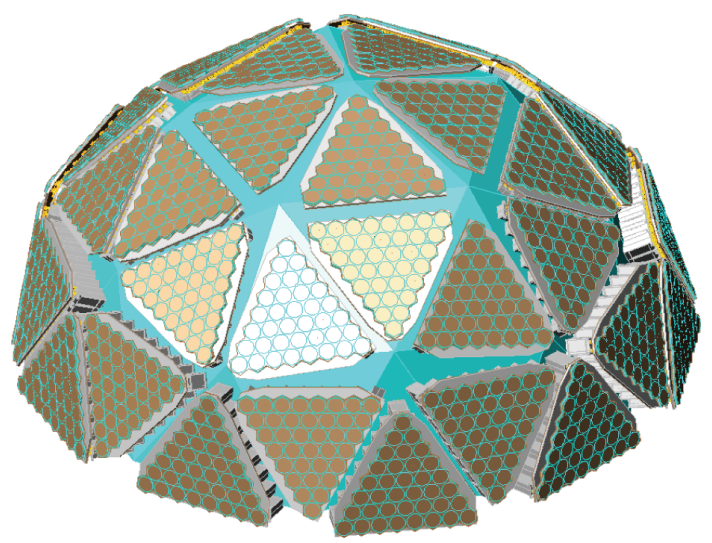

FIGURE 3: Faceted hemi-spherical antenna.

Each triangular subarray, indicated as tile, presents 36 radiating elements.

For a fixed beam direction only a sector composed by 14 tiles is active while all the other elements are turned off. All the radiating elements in the active sector are excited in order to generate an equal-phase wave front perpendicular to the desired beam direction.

The antenna block diagram, presented in Figure 4, is representative of the antenna electrical architecture.

The input/output ports are fed with the IF band signal, and they are converted in a Ku band signal by the up/down converter. Two dedicated beam forming networks $1: 40$ for the receive and the transmit mode are connected to the tiles, and the CPU controls a set of switches in order to involve the selected subarrays to form the antenna beam. Each tile is composed by the radiating elements and the transmit/receive modules, directly connected behind. The CPU controls the beam steering and the polarization alignment.

\section{Antenna Description}

The antenna works simultaneously in reception and transmission on the entire $\mathrm{Ku}$ band $(10.7 \mathrm{GHz} / 12.75 \mathrm{GHz}$ in $\mathrm{Rx}$; 14.0 GHz/14.5 GHz in Tx). A deep investigation, optimization, and trade-off have been implemented in order to identify the wide-band radiating element. 


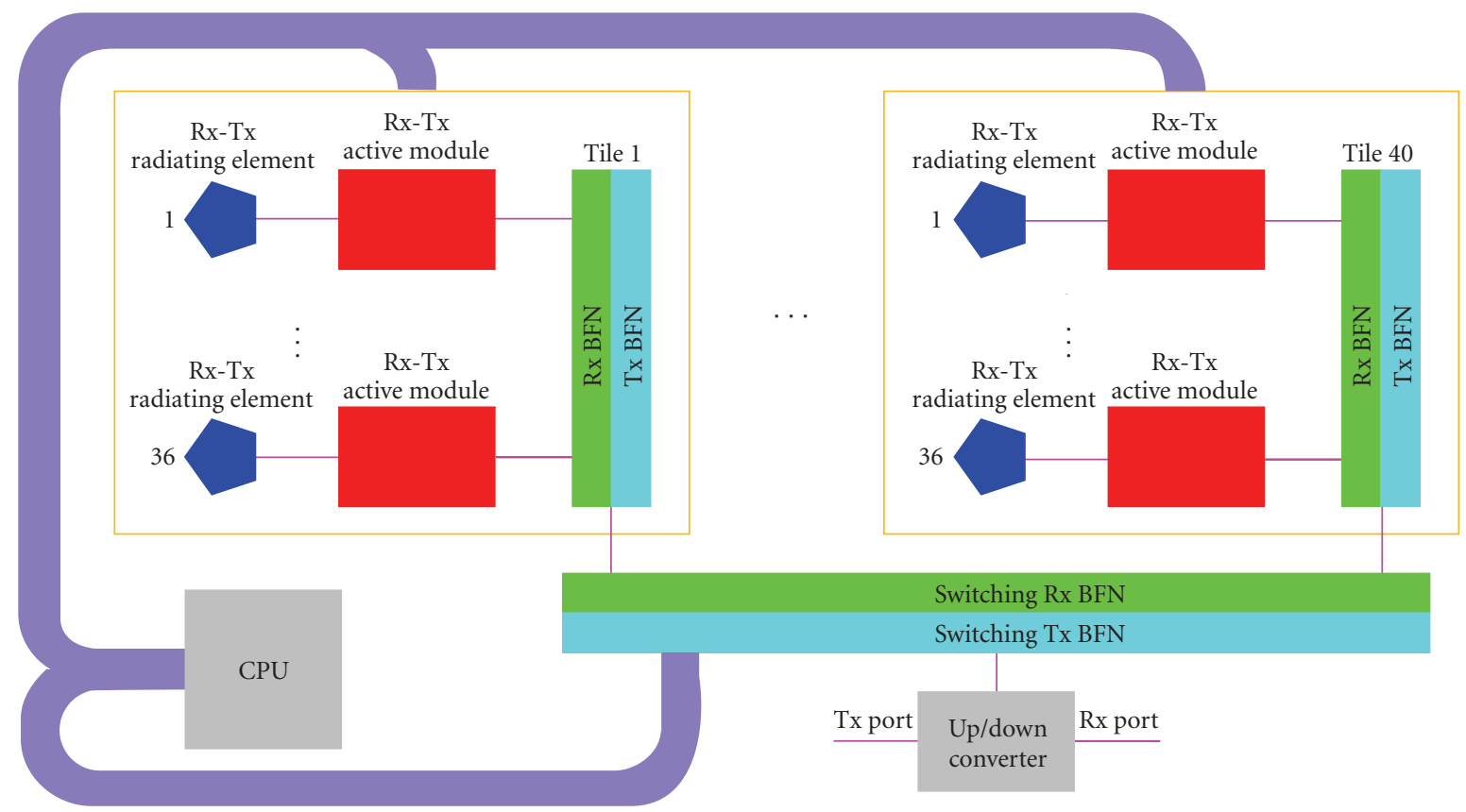

FIgURE 4: Hemi-spherical antenna block diagram.

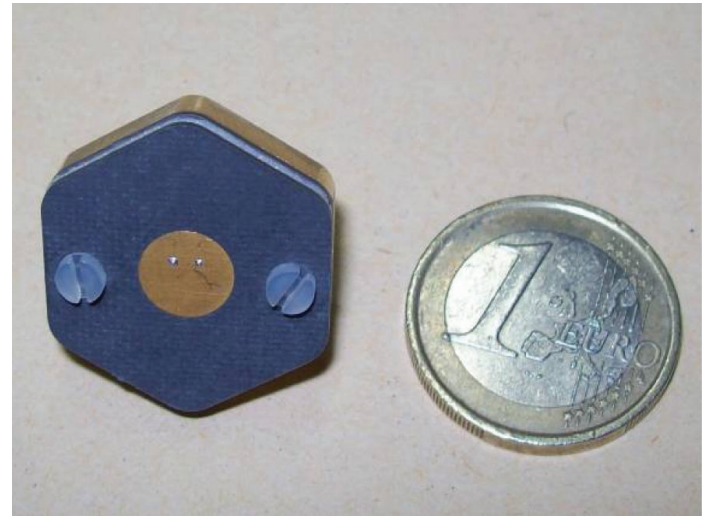

FIGURE 5: Radiating element prototype.

3.1. Passive Radiating Module. Two possible solutions are envisaged:

(i) the first one is based on a wideband or dual band radiating element; in order to separate the receive signal from the transmit signal it is mandatory the use of a circulator or a diplexer;

(ii) the second one is based on a self-diplexing radiating element; this element presents four physical ports (two for Rx, two for Tx). The self-diplexing element has the advantage to minimize the ohmic losses, therefore improving both the G/T and the EIRP.

The selected solution is based on a self-diplexing radiating element. It offers better electrical performances and permits reducing the manufacturing complexity.

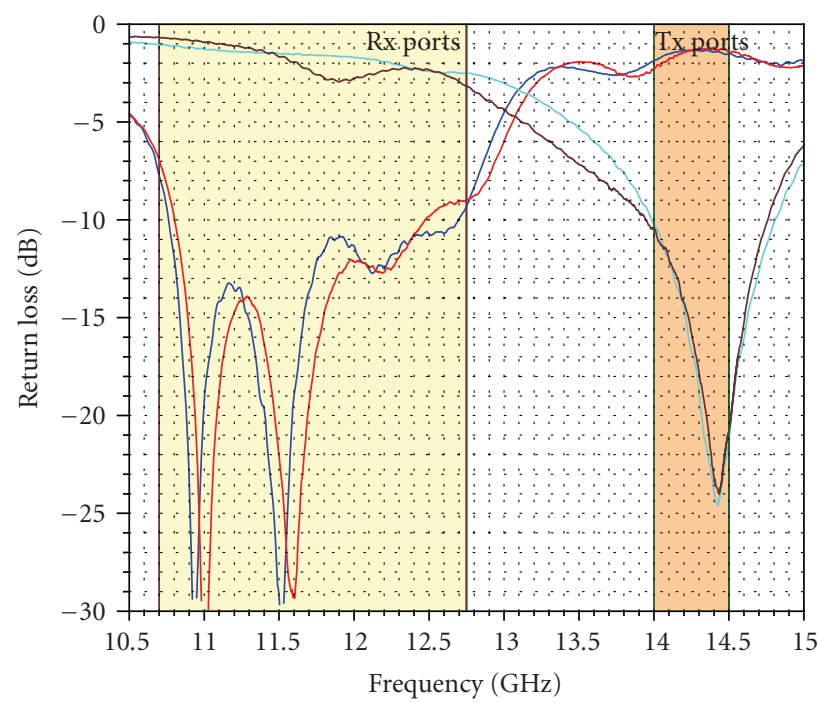

Figure 6: Measured radiating element return loss.

A prototype of the realized radiating element is shown in Figure 5. The measured performances of the radiating elements in terms of Return Loss are reported in Figure 6. The isolation between the ports is better than $20 \mathrm{~dB}$ over the operative bands.

The radiation patterns of the radiating element at the center frequency in the receive and transmit band are shown in Figures 7 and 8.

3.2. B. Tx/Rx Active Module. Each radiating element presents an active circuitry directly connected to the output ports 


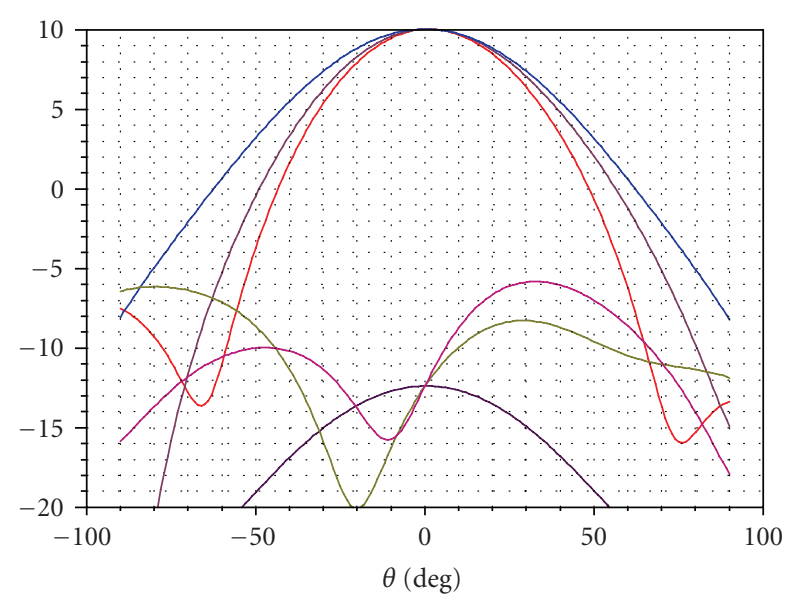

FIgURE 7: Simulated radiating pattern in receive.

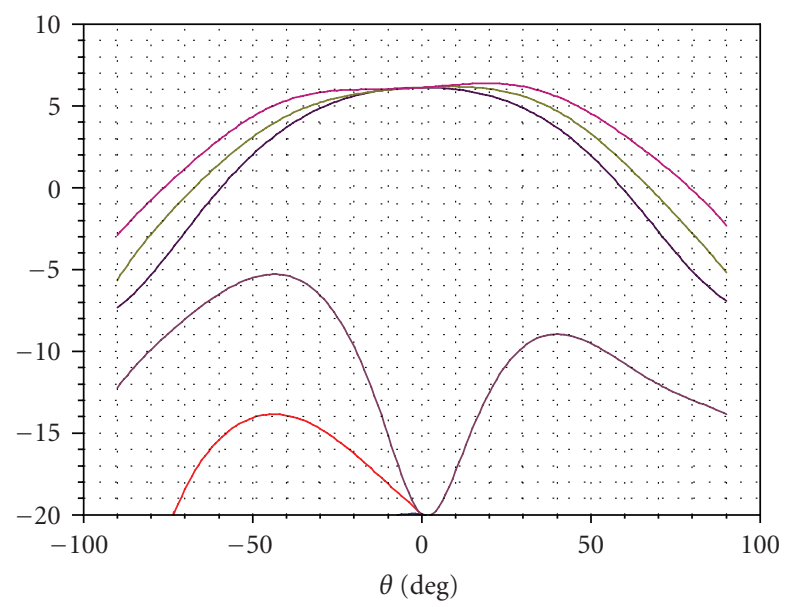

FIGURE 8: Simulated radiating pattern in transmit.

( $\mathrm{Tx} / \mathrm{Rx}$ module). The $\mathrm{Tx} / \mathrm{Rx}$ module is able to realign the linear polarization in receive and in transmit or, otherwise, it is able to generate a circular polarization [6]. The phase shifters used for the polarization control are able at the same time to form the antenna beam imposing the correct relative phase between the elements. The active modules are composed by the receive device and the transmit device (the assembled $\mathrm{Tx} / \mathrm{Rx}$ device is shown in Figure 9).

The manufactured modules are presented in Figure 10: in particular the control board sides are shown. of $15 \mathrm{~g}$.

Their dimensions are $20.6 \times 7 \times 37 \mathrm{~mm}^{3}$, with a weight

As mentioned, each $\mathrm{Tx} / \mathrm{Rx}$ Active Module is directly connected to the passive radiating elements (see Figure 9), and they are arranged in a triangular lattice with a number of 36 in order to compose the triangular subarray, that is, the tile of the Hemi-Spherical Antenna (Figure 11).

Two dedicated equal-amplitude and equal-phase beam forming networks combine the transmit and the receive signals coming from the active module (Figure 12).

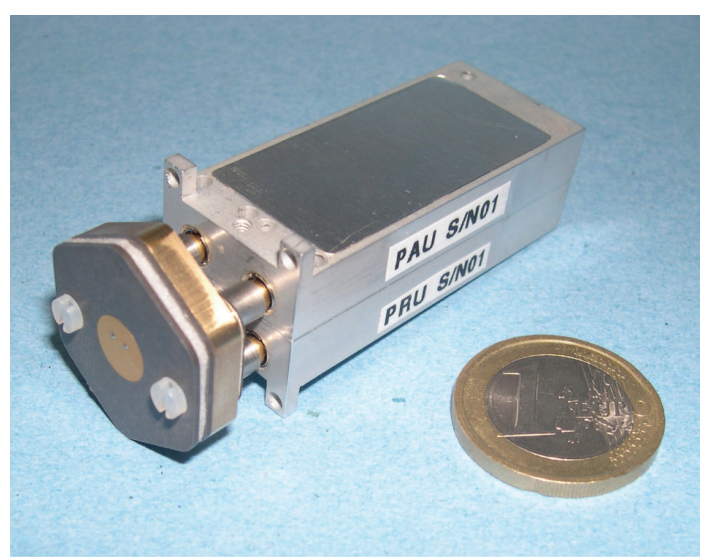

Figure 9: Tx/Rx active module connected to the radiating element.

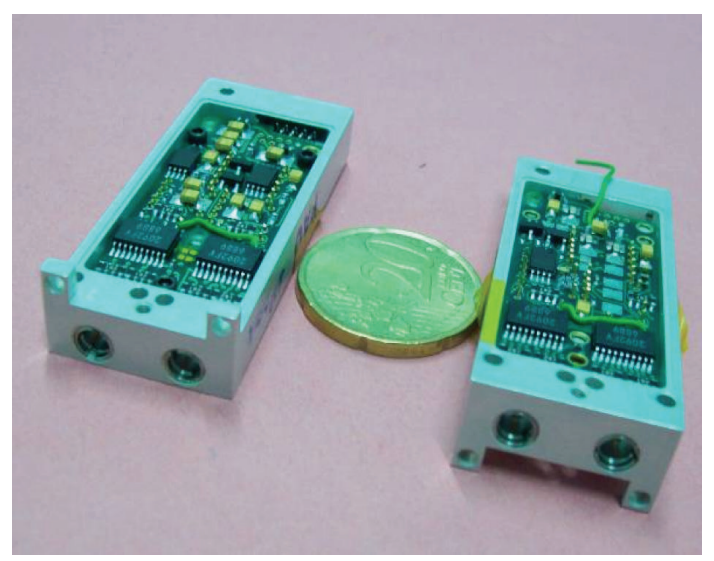

Figure 10: Tx and Rx active device-control board view.

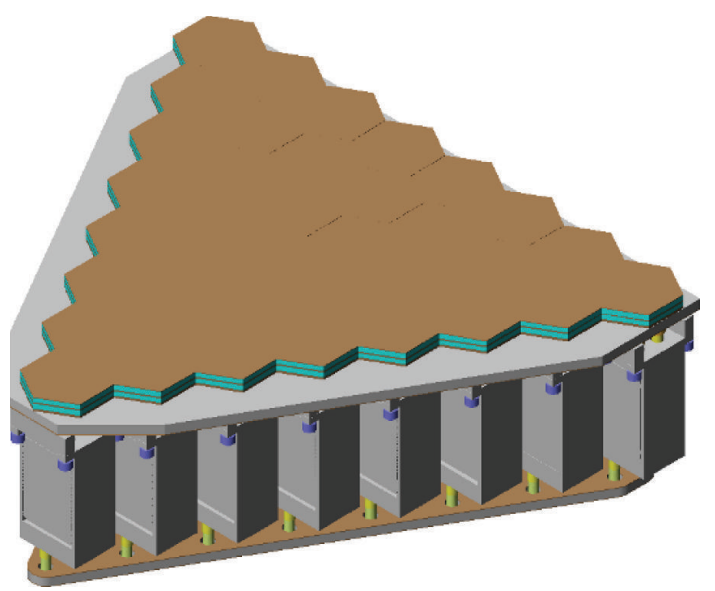

FIGURE 11: Tile of the hemi-spherical antenna.

Using the micro-coaxial cable, all the $\mathrm{Rx}$ and $\mathrm{Tx}$ ports behind the tiles are combined in two dedicated switching BFNs that are able to transmit and receive the signal of the selected tile. As mentioned, only a dedicated number of tiles, 14, are active instantaneously depending on the azimuth and elevation beam pointing. A micro-PC has controled 


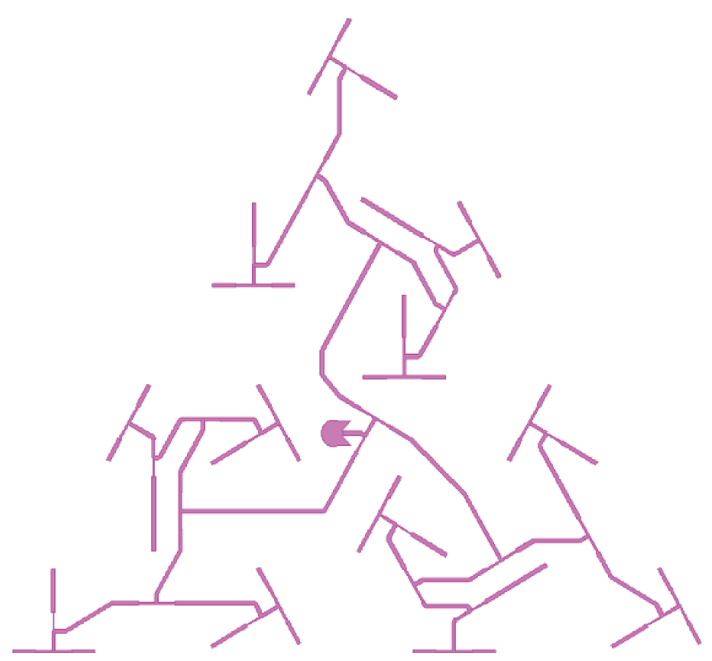

FIGURE 12: Receive BFN layout.

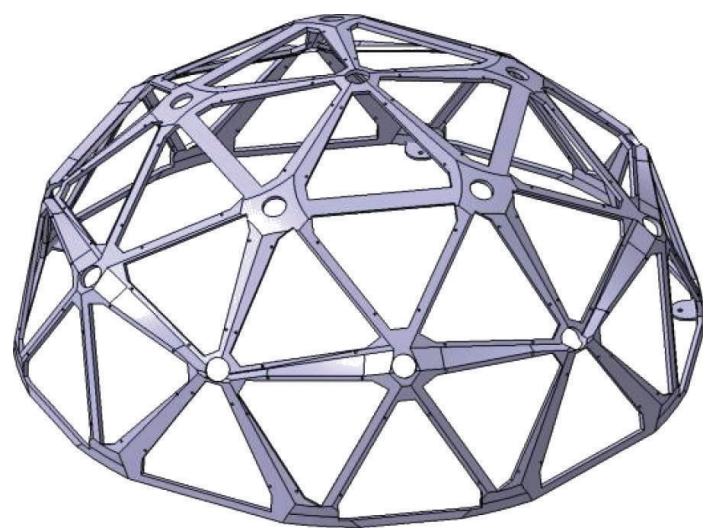

Figure 13: Antenna structure.

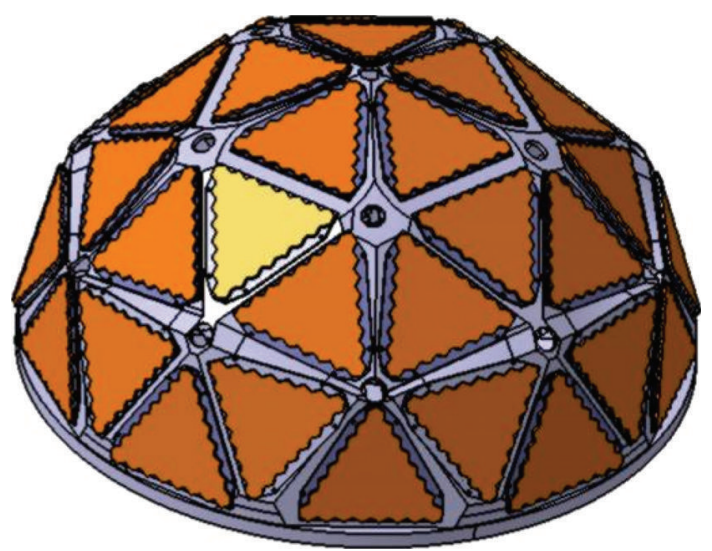

Figure 14: Assembled Hemi-Spherical antenna.

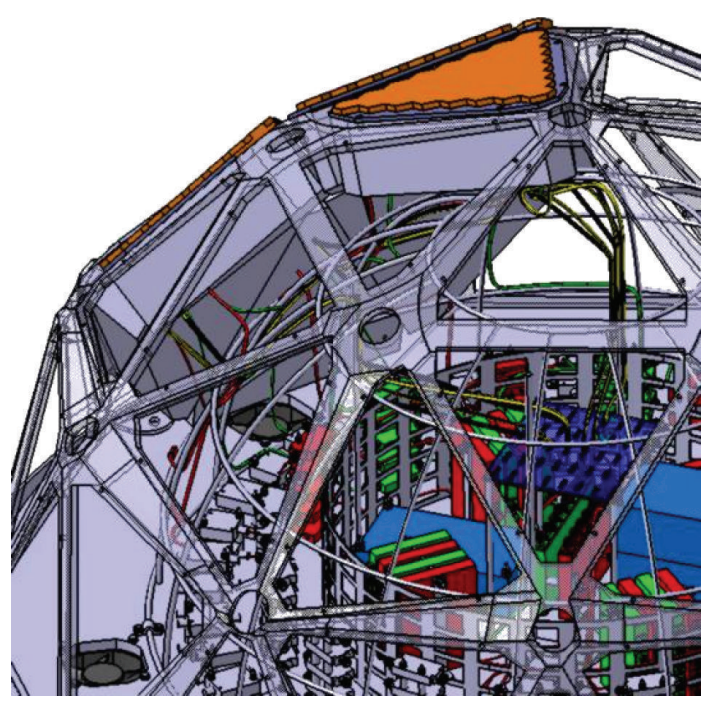

FIGURE 15: Cable routing of a part of the antenna. all the active components taking into account the satellite position and the aircraft attitude. The beam forming network connecting the tiles is realized using commercial microwave components.

The tiles are positioned on the shell-shaped structure, shown in Figure 13, which can be manufactured by a casting process or by the assembly of simple part obtained by a numerical control machine.

The result of the assembled hemi-spherical antenna is presented in Figure 14. Some details of the inner part considering the cable routing between the tiles and the switching beam forming network are presented in Figure 15.

\section{Antenna Performances}

The tracking capability of the antenna permits to point the beam electronically in a hemi-spherical field of view (i.e., 360 degrees in azimuth and 90 degrees in elevation) with reduced degradations of the electrical performances, guaranteeing a minimum $\mathrm{G} / \mathrm{T}$ of $8 \mathrm{~dB} / \mathrm{K}^{-1}$ and an EIRP of $43 \mathrm{dBW}$.

The results are obtained using the simulated pattern of an embedded radiating element. Moreover, in the optimization of the excitation coefficients, the realistic functionality of the $\mathrm{Rx} / \mathrm{Tx}$ active module (combining the amplitude and phase of the two orthogonal polarization for each radiating element) has been taken into account.

The G/T is shown in Figure 16: as can be seen, the performances match the required $8 \mathrm{~dB} / \mathrm{K}$ in the entire field of view. The obvious decreasing of performance at the lower pointing angles is due to different orientation angles of the tiles, involved in the beam forming, with respect to the horizon. The typical azimuth receive antenna pattern is shown in Figure 17.

In transmit all the active devices are able to work at the maximum power level, and the foreseen performance in term of EIRP is reported in Figure 18: the minimum guaranteed performance is in the order of $43 \mathrm{dBW}$ over the complete antenna field of view. 


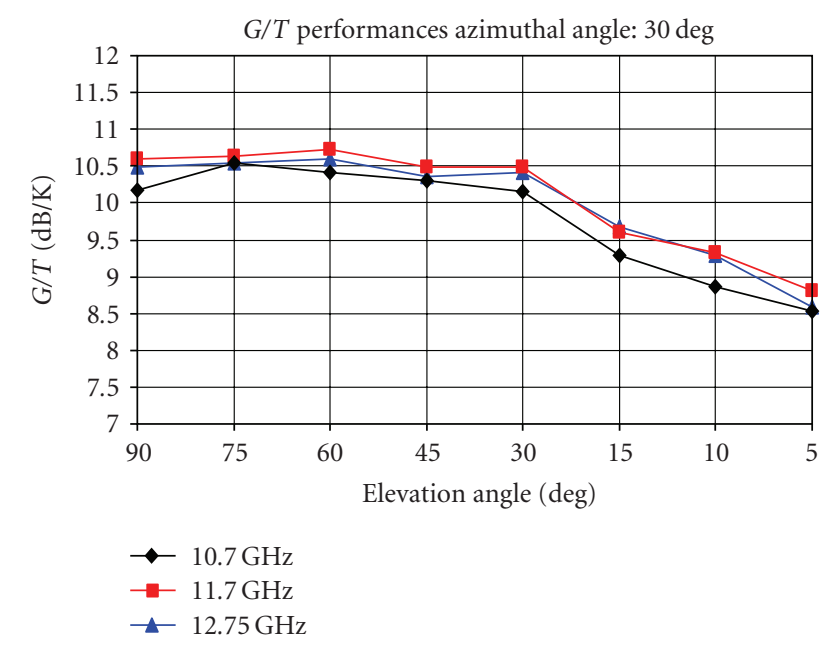

Figure 16: G/T versus elevation angle over the horizon.
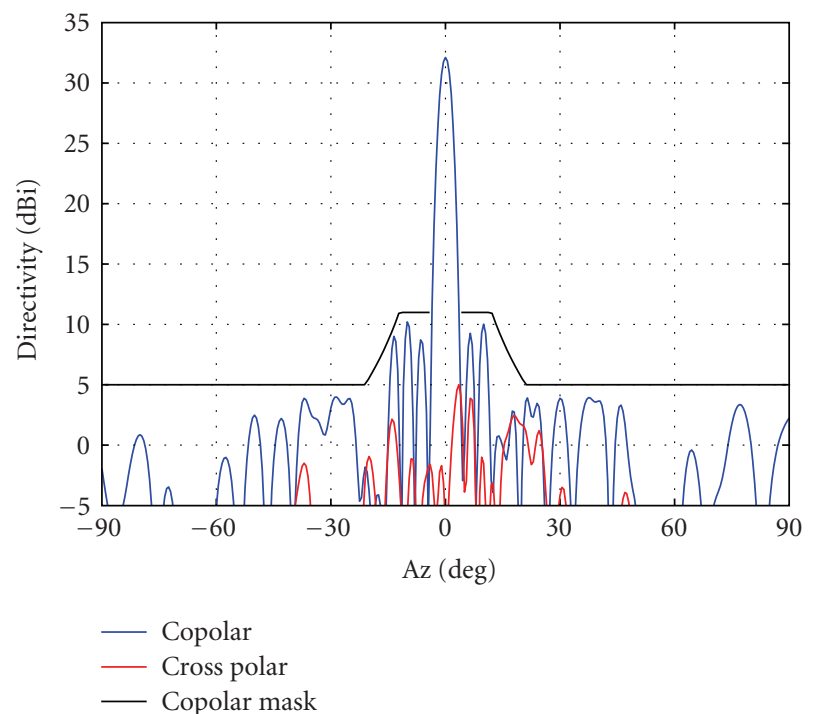

Figure 17: Azimuth Rx Antenna Pattern at $11.7 \mathrm{GHz}$, considering a $30^{\circ}$ elevation pointing over the horizon.

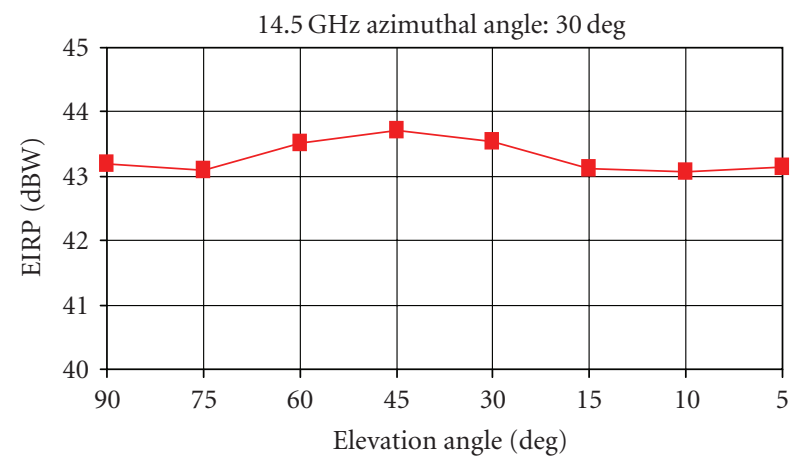

FIGURE 18: EIRP versus elevation angle over the horizon.

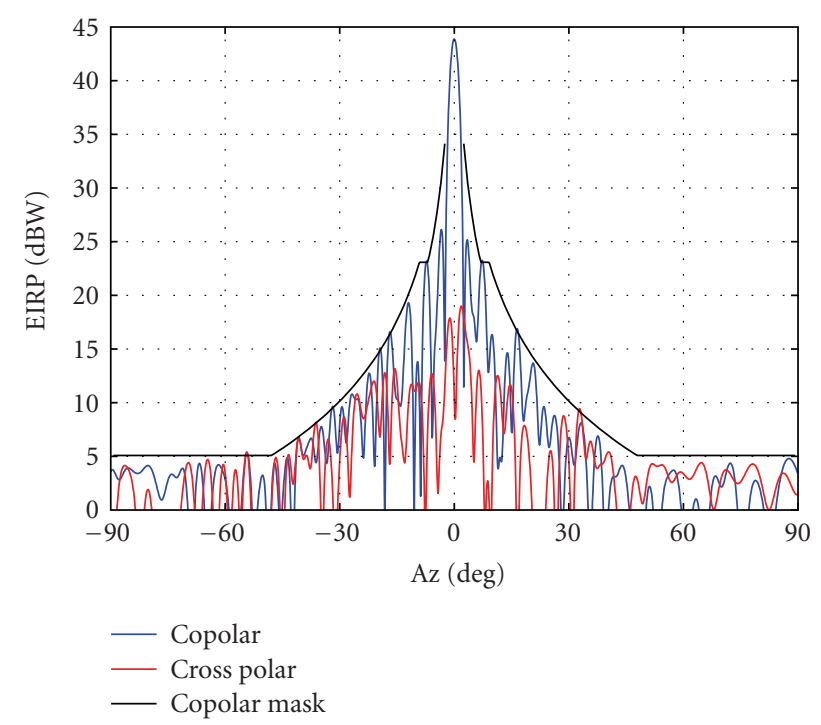

Figure 19: Typical Azimuth Tx Antenna Pattern at $14.25 \mathrm{GHz}, 30^{\circ}$ elevation pointing over the horizon.

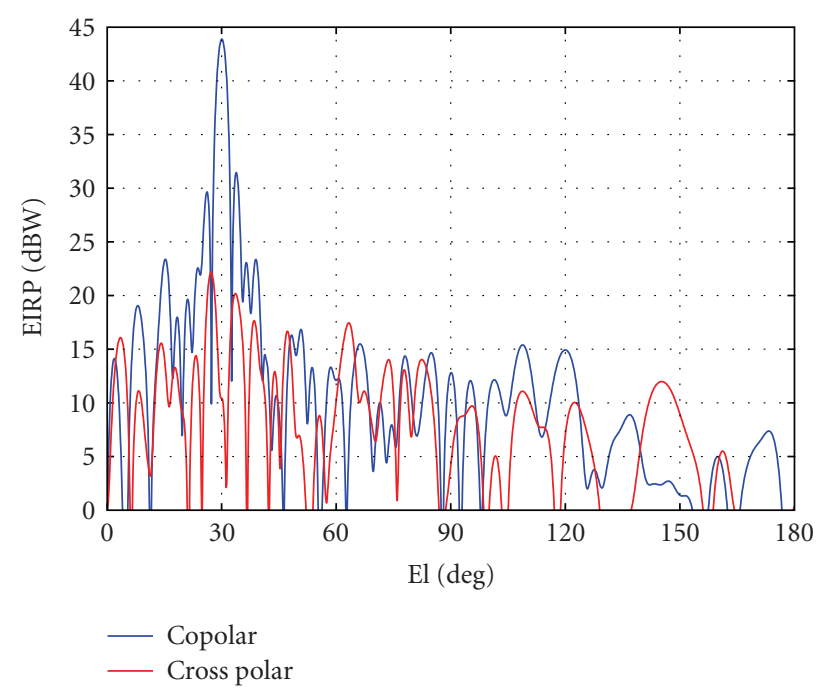

Figure 20: Typical Elevation Tx Antenna Pattern at $14.25 \mathrm{GHz}, 30^{\circ}$ elevation pointing over the horizon.

The antenna is also able to control the transmit antenna patterns side-lobe in order to respect the applicable regulatory recommendations such as ETSI in the European countries [5, 7] and the FCC in the United States.

The typical azimuth transmit antenna pattern is presented in Figure 19. The black line represents the mask that has been imposed in the optimization process (corresponding to the ETSI mask for $512 \mathrm{KHz}$ bandwidth). Also the correspondent elevation transmit antenna pattern is shown in Figure 20.

\section{Conclusion}

In the paper the results of the activities carried out in the frame of the ESA Contract "Advanced Antenna Concepts For Aircraft In Flight Entertainment” have been presented. 
The designed Ku band active antenna exhibits a compact size and the possibility of full beam pointing coverage. The antenna radiating element module is providing also polarization alignment capabilities in transmission and reception.

The antenna exhibits really good technical performances. The next activities will be focused on reducing dimension, cost, and complexity of the entire antenna in order to meet the severe expectation of a market product.

\section{Acknowledgments}

The authors acknowledge the colleagues R. Pasta and L. Flamini for UTRI; A. Toresin for Aeronavali; E. Limiti for the University of Roma Tor Vergata; S. Selleri for the University of Florence for their support and contribution in the activity.

\section{References}

[1] G. Bellaveglia, L. Marcellini, A. Ferrarotti, S. Arenaccio, and R. Lo Forti, "Two-way low profile satellite antenna system for mobile applications," in Proceedings of the 30th ESA Antenna Workshop on Antennas for Earth Observation, Science, Telecommunication and Navigation Space Missions, Noordwijk, The Netherlands, May 2008.

[2] C. O. Adler, A. D. Monk, D. N. Rasmussen, and M. J. Taylor, "Two-way airborne broadband communications using phased array antennas," in Proceedings of IEEE Aerospace Conference, vol. 2, pp. 925-932, Big Sky, Mont, USA, March 2003.

[3] P. Halsema, B. Anderson, and J. Frisco, "Airborne DBS receive system," in Proceedings of Antennas and Propagation Society International Symposium, Montreal, Canada, July 1997.

[4] M. Shelley, R. Pearson, and J. Vazquez, "Low profile, dual polarised antenna for aeronautical and land mobile satcom," in Proceedings of the 4th Advanced Satellite Mobile Systems (ASMS '08), pp. 16-19, Bologna, Italy, August 2008.

[5] ETSI EN 302186 V1.1.1 (2004-01), "Satellite Earth Stations and Systems (SES); Harmonized EN for satellite mobile Aircraft Earth Stations (AESs) operating in the $11 / 12 / 14 \mathrm{GHz}$ frequency bands covering essential requirements under article 3.2 of the R\&TTE Directive".

[6] "A system for electronically aligning the polarization of an antenna," Italian Patent no. IT/20.03.07/ ITA RM20070144, European Patent Appl. no./Patent no. 08425163.6 - 2220.

[7] Recommendation ITU-R M.1643, "Technical and operational requirements for aircraft earth stations of aeronautical mobilesatellite service including those using fixed-satellite service network transponders in the band $14-14.5 \mathrm{GHz}$ (Earth-tospace)," 2003. 

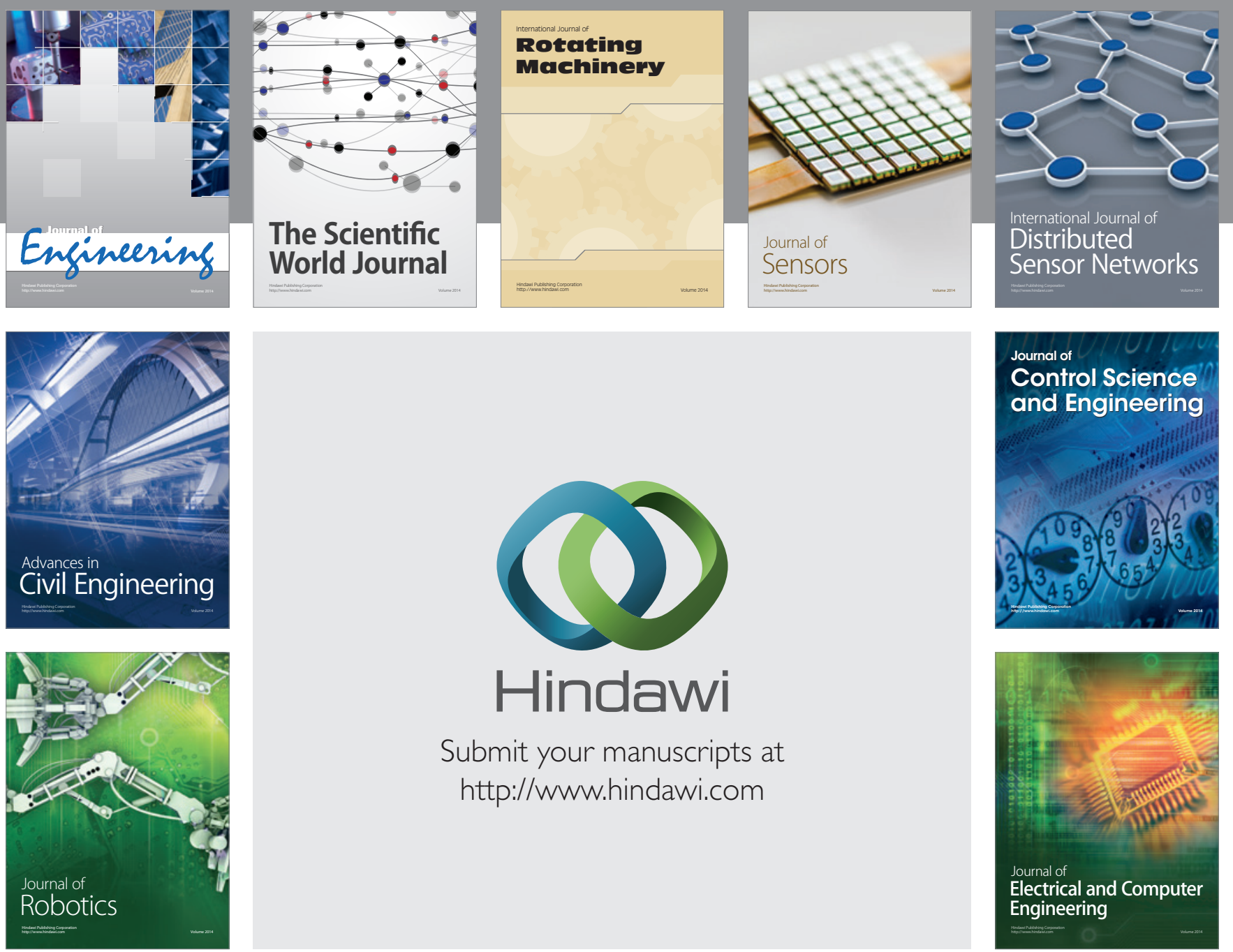

Submit your manuscripts at

http://www.hindawi.com
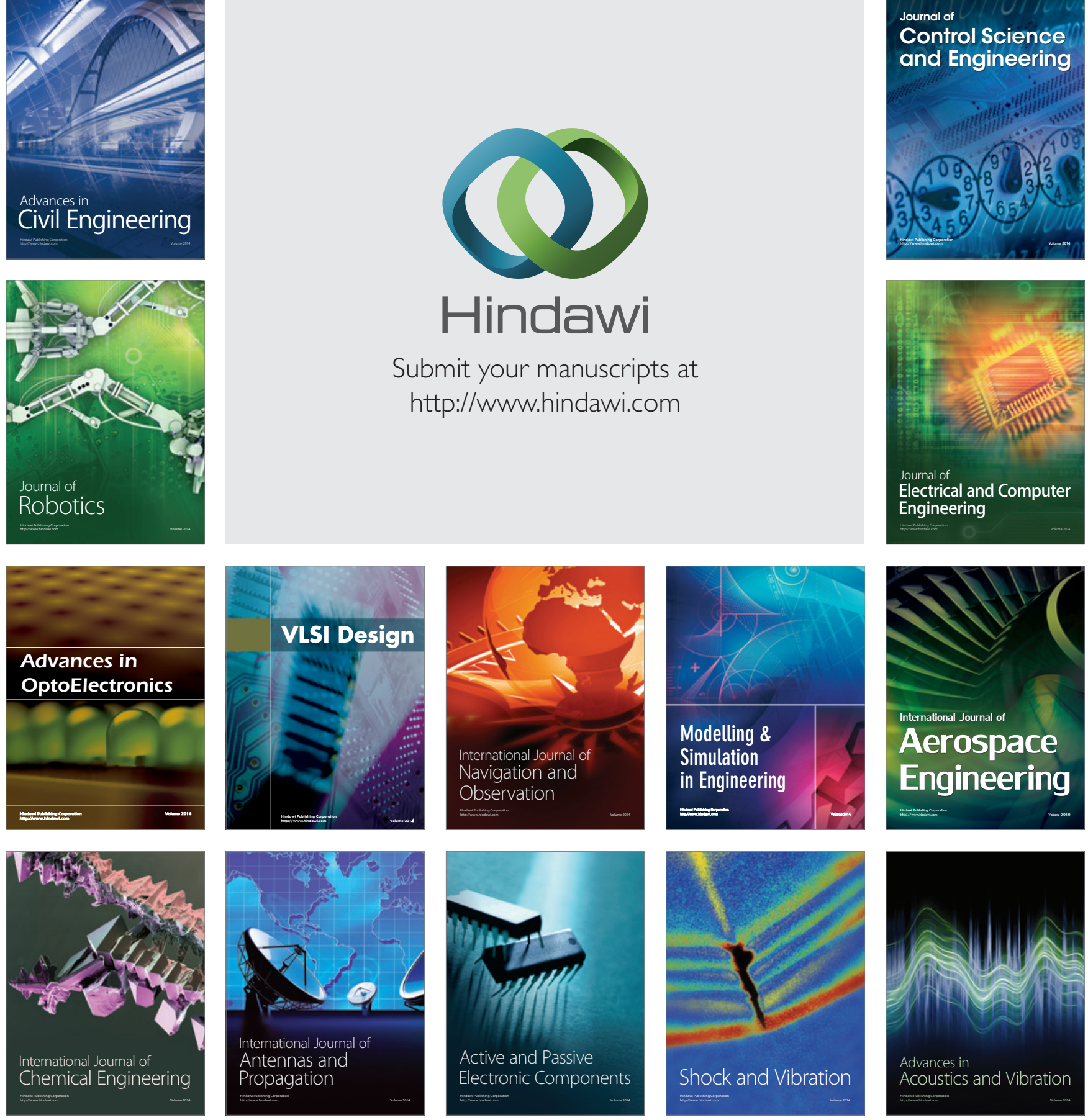